\title{
Homocystinuria
}

\section{Reduced folate levels during pyridoxine treatment}

\author{
BRIDGET WILCKEN and BRIAN TURNER* \\ From the Oliver Latham Laboratory, The Psychiatric Centre, North Ryde, Sydney, N.S.W., Australia
}

\begin{abstract}
Wilcken, B., and Turner, B. (1973). Archives of Disease in Childhood, 48, 58. Homocystinuria: reduced folate levels during pyridoxine treatment. Nine patients with homocystinuria due to cystathionine synthase deficiency were treated with pyridoxine: 6 responded biochemically and 5 of these showed marked clinical improvement. Full biochemical response was only obtained slowly in some patients. Response occurred in those patients who were least severely affected by their disease and was consistent within families. No patient experienced a thrombotic episode during pyridoxine treatment. Pretreatment serum and red cell folate levels were normal. All patients showed lowering of folate levels while receiving pyridoxine, and administration of folic acid caused further biochemical improvement in pyridoxine responsive patients and subjective clinical improvement in all. The mechanism for lowering of folate levels during pyridoxine administration may depend upon removal of substrate inhibition of the enzyme $\mathrm{N}^{5}$ methyltetrahydrofolate homocysteine methyl transferase, due to pyridoxine-induced lowering of the substrate homocysteine. It is suggested that patients with homocystinuria should be given a long trial with pyridoxine and that folic acid should be given in all cases where pyridoxine is used.
\end{abstract}

Homocystinuria due to cystathionine synthase deficiency was first described in 1962 by Carson and Neill, and Gerritsen, Vaughn, and Waisman. Since then many cases have been described and the clinical syndrome is well known (McKusick, Hall, and Char, 1971a). The metabolic defect, first shown by Mudd and his co-workers in 1964, causes accumulation of homocystine, methionine, and intermediate metabolites, and the synthesis of cystathionine and cystine is blocked. (Homocystine and cystine occur in the plasma and tissues as the reduced forms, homocysteine and cysteine, and their mixed disulphide. However, they are measured in the oxidized forms and will be referred to thus throughout this paper.)

It has not so far been possible to relate with certainty the biochemical abnormalities to the pathological changes seen in this condition, though McCully (1970) has made several interesting observations. Treatment of homocystinuria has usually been directed towards lowering the plasma levels of methionine and homocystine. This has

Received 5 May 1972.

^Present address: Fulton Laboratories, Royal Alexandra Hospital for Children, Camperdown, N.S.W., Australia. been attempted by a low methionine diet with supplemental cystine (e.g. Perry et al., 1966), by气 supplementation with the enzymatic co-factoro pyridoxine (Barber and Spaeth, 1969), and by $\overrightarrow{\vec{B}}$ attempting to increase the remethylation of homo- 3 cystine to methionine with choline, betaine, folic acid, and vitamin B12 (Perry et al., 1968; Sard-0 harwalla et al., 1968; Carey, Fennelly, and FitzGerald, 1968; Hollowell et al., 1968).

We report here our experiences with 9 patients 0 who were treated with pyridoxine. Changes in the levels of serum and red cell folate activity wereô estimated and the effects of adding folic acid to the treatment regimen investigated.

\section{Patients and methods}

The patients were 9 children from 5 sibships (see N Table). The clinical condition has been classed as ${ }^{\circ}$ mild, moderate: or severe. The 'severe' patients all 응 showed the complete clinical picture of homocystinuria N with mental retardation, severe skeletal abnormalities, $\sigma$ ectopia lentis, and thrombotic episodes. Those patients classed as mild had no mental retardation, only slight $\subset$ skeletal abnormalities and no ectopia lentis. 'Moderate' cases fell between these two extremes. All had lens? dislocation, mild intellectual impairment, and moderate $T$ 
TABLE

Clinical data, response to pyridoxine, and serum and red cell folate levels in 9 homocystinuric patients

\begin{tabular}{|c|c|c|c|c|c|c|c|}
\hline Case no. & $\begin{array}{c}\text { Age at } \\
\text { diagnosis } \\
(y r)\end{array}$ & Sex & $\begin{array}{l}\text { Clinical } \\
\text { condition }\end{array}$ & $\begin{array}{c}\text { Response } \\
\text { to } \mathrm{B} 6\end{array}$ & $\begin{array}{l}\text { Serum FAA } \\
\text { pretreatment } \\
(\mathrm{ng} / \mathrm{ml})\end{array}$ & $\begin{array}{l}\text { Lowest serum } \\
\text { FAA during } \\
\text { treatment }\end{array}$ & $\begin{array}{c}\text { Lowest RCFAA } \\
\text { during } \\
\text { treatment }\end{array}$ \\
\hline $\begin{array}{l}\left\{\begin{array}{l}1^{\star} \\
2^{\star}\end{array}\right. \\
\left\{\begin{array}{l}3 t \\
4 \dagger \\
5 t\end{array}\right. \\
6\end{array}$ & $\begin{array}{c}7 \\
21 / 12 \\
11 \\
8 \\
8 \\
8 \\
6 \\
3 / 12 \\
29 / 12\end{array}$ & $\begin{array}{l}\mathrm{F} \\
\mathrm{M} \\
\mathrm{F} \\
\mathrm{M} \\
\mathrm{M} \\
\mathrm{F} \\
\mathrm{M} \\
\mathrm{F} \\
\mathrm{M}\end{array}$ & $\begin{array}{l}\text { Severe } \\
\text { Severe } \\
\text { Mild } \\
\text { Mild } \\
\S \\
\text { Moderate } \\
\text { Moderate } \\
\text { Normal } \\
\text { Moderate }\end{array}$ & $\begin{array}{l}\text { No } \\
\text { No } \\
\text { Yes } \\
\text { Yes } \\
\text { Yes } \\
\text { Yes } \\
\text { No } \\
\text { Yes } \\
\text { Yes }\end{array}$ & $\begin{array}{l}\bar{Z} \\
7 \cdot 2 \\
7 \cdot 0 \\
4 \cdot 2 \\
\bar{Z} \\
5 \cdot 2 \\
4 \cdot 2\end{array}$ & $\begin{array}{l}1 \cdot \overline{7} \\
3 \cdot 5 \\
3 \cdot 3 \\
2 \cdot \overline{2} \\
2 \cdot 1 \\
1 \cdot 8\end{array}$ & $\begin{array}{r}\overline{141} \\
178 \\
\overline{-} \\
\overline{74} \\
96 \\
134 \\
145\end{array}$ \\
\hline
\end{tabular}

FAA $=$ folic acid activity RCFAA $=$ red cell folic acid activity. Sibships indicated by braces.

Serum FAA levels below $5 \mathrm{ng} / \mathrm{ml}$, and more particularly red cell FAA levels below $170 \mathrm{ng} / \mathrm{ml}$ are considered lower than normal.

$\star$ Previously reported as Cases 5 and 6 (Turner, Dey, and Turner, 1967).

†Mentioned by McKusick, Hall, and Char (1971b).

$¥$ See text.

$\$$ Poor clinical condition due mainly to birth trauma, not homocystinuria.

skeletal abnormalities. Fasting plasma amino acids were estimated on at least two occasions, with an interval of two weeks, before any treatment was begun. Blood collected for amino acid analysis was heparinized. The plasma was separated within 10 minutes, and protein precipitated with picric acid; the supernatant was frozen until measurements could be made. Amino acids were measured on a Beckman Unichrome amino acid analyser.

Serum and red cell folic acid was assayed by a microbiological method using Lactobacillus case $i$ as the test organism. Serum B12 estimations were made using Euglena gracilis. In 5 patients, pretreatment folate estimations were made. 7 patients had serial estimations of folate levels during treatment.

All patients were treated with pyridoxine, usually in a daily dose of $500 \mathrm{mg}$ as a suspension of pyridoxine hydrochloride 5\% (Ethnor). One, a baby, received approximately $100 \mathrm{mg} /$ day. Patients were considered to respond to pyridoxine therapy if they showed a drop in fasting plasma methionine to normal or near-normal levels, a disappearance of plasma homocystine on most occasions, and a rise in plasma cystine to normal levels.

Seven of these patients, Cases 2 to 4 and 6 to 9, were subsequently treated with folic acid. Initially we gave $10 \mathrm{mg} /$ day, orally, and later $5 \mathrm{mg} /$ day.

No other form of treatment was given to the patients. The diets were their normal diets, though a moderate degree of protein restriction was advised.

\section{Results}

Response to pyridoxine. 6 out of 9 patients (see Table) responded to pyridoxine with a drop in plasma methionine and homocystine levels and a rise in plasma cystine. These changes were evident when the first blood sample was taken two weeks after treatment began, but plasma levels of methionine and homocystine continued to fall over a longer period of from 3 to 6 months. In one patient (Case 6), near-normal fasting levels of plasma methionine and cystine, and very low levels of homocystine were attained only intermittently over a period of 5 months; when folic acid was added to the treatment regimen, plasma levels of methionine and cystine became normal and homocystine could not be detected (see Fig.).

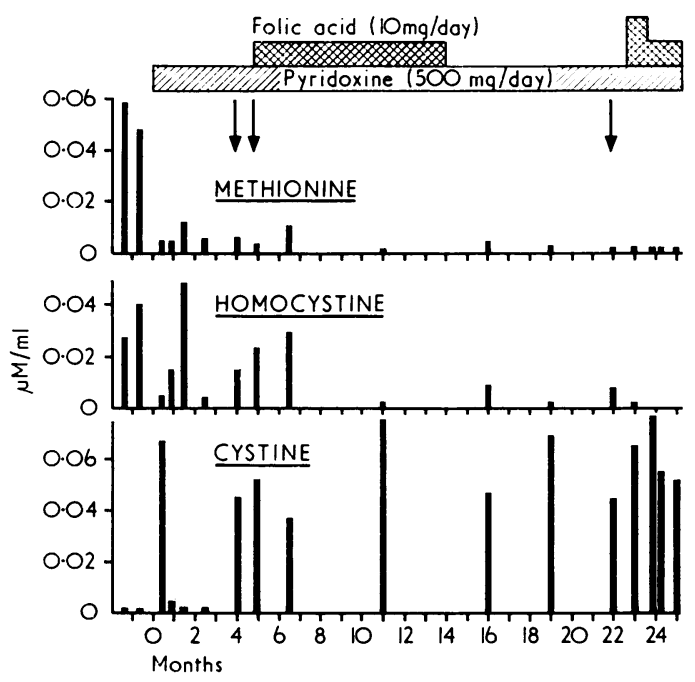

FIG.-Case 6: Response of plasma methionine, homocystine, and cystine to oral pyridoxine and folic acid. Arrows indicate low serum and red cell folate levels.

There was a quite obvious improvement in behaviour in all patients who responded biochemically to pyridoxine, except in one (Case 5), in 
whom treatment was for a short period only. School records improved in two (Cases 3 and 4), and in all, the parents reported increased energy and lessening of irritability, both of which were quite striking to the authors. In one child, attacks akin to petit mal, which had been frequent, ceased. No patient suffered any thrombotic episode while being treated with pyridoxine whether or not any biochemical response was shown, over a total of 16 patient-years. During this period one child (Case 1), not then on pyridoxine, suffered a fatal cerebral thrombosis, and one very mildly affected patient (Case 3 ) had a probable cerebral thrombosis during a period when her pyridoxine therapy had been stopped at another centre. She has now resumed this therapy.

One patient (Case 7) appeared to have a partial biochemical response for three months but there was no increase in plasma cystine and no behavioural improvement. By 6 months, plasma levels of methionine and homocystine were above pretreatment levels. 2 children (Cases 1 and 2) showed no response at all, either biochemically or behaviourally. Both were severely affected by their disease, and one (Case 1) has since died of a cerebral thrombosis.

The response was consistent within families; 2 pairs of sibs responded fully, and one pair did not. The 3 patients who did not respond were the 3 most severely affected of the series.

Folate levels and response to treatment with folic acid. Pretreatment levels of serum folic acid were normal (see Table). 2 of 3 patients already receiving pyridoxine had low serum folate levels $(3.4 \mathrm{ng} / \mathrm{ml}$ after 4 months', and $2 \cdot 7 \mathrm{ng} / \mathrm{ml}$ after 2 years' treatment). One patient (Case 7 ), who appeared to respond partially to pyridoxine for 3 months, had normal serum and red cell folate levels after 18 months' pyridoxine treatment. For 16 months of this period he had had very high levels of plasma homocystine (up to $0.16 \mu \mathrm{mol} / \mathrm{ml}$ ), after which homocystine fell and methionine rose. After a further 6 months of pyridoxine he had very low levels of folate. During pyridoxine treatment, serum and red cell folate levels fell in every patient in whom they were measured. Lowering of levels was apparent after 2 to 5 months in pyridoxineresponsive cases. It had not occurred until 20 months in the partially-responding Case 7 mentioned above.

No patient developed anaemia, and there were no morphological changes seen in the blood cells, despite some prolonged low levels of red cell folate activity ( 8 estimations between 74 and 148 . $\mathrm{ng} / \mathrm{ml}$ in 3 patients who had had low levels for up to 9 months). Haemolysates of 2 patients with low folic acid activity did not inhibit the growth of Lactobacillus casei when folic acid was added tos the culture medium. Serum B12 levels weres within normal limits at all times in each patient.

Irritability or temper tantrums were associated with low folate levels in at least 4 of our patientso (Cases 6 to 9), and these subsided within a week of beginning treatment with folic acid. Whereas, in the cases who were not responding biochemicallyo to pyridoxine, folic acid supplementation increasedplasma methionine levels and reduced homocystine ${ }_{\mathrm{D}}^{\omega}$ this effect was either absent or transient in thosen cases in which pyridoxine therapy was biochemicallyo effective.

The Figure illustrates the plasma methionine:homocystine, and cystine levels during over 2 yearsi of treatment with pyridoxine and folic acid ino Case 6, a girl now aged 11, who is only mildly? retarded, has dislocation of the lenses, and slighte skeletal abnormalities.

\section{Discussion}

Since treatment of homocystinuria with the co- $\vec{\theta}$ factor pyridoxine was first suggested by Spaesh and Barber in 1965, there have been reports $\$ \dot{f}$ over 50 cases treated (e.g. Carson and Cancis? 1969; Brenton and Cusworth, 1971). Appro mately half have shown a good biochemical response, with lowering of plasma and urinary methionine, $\$$ disappearance of homocystine, and increases in cystine levels. We obtained similar results in ouro study. In our series, those who responded were less severely affected clinically than those who did not, and Brenton and Cusworth (1971) have somewhat similar findings. In 3 patients whoo responded to pyridoxine, some months elapsed? before their response became complete, with normal plasma levels of methionine and cystine, and disappearance of homocystine. This is in con- $\frac{\mathrm{O}}{3}$ trast to the findings of Carson (1971) who found a clear response after one week in all 7 of hero responding patients. It could indicate that tissue stores of methionine and its metabolites must be reduced before plasma levels are substantially altered. It also suggests that a prolonged trial of pyridoxine may be justified in patients who show an incomplete biochemical response. In ourw patients, the response to pyridoxine was consistent within families. This has been so in all reportedo cases, so that our results lend further support to the suggestion that response to pyridoxine is genetically? determined. The improvement in behaviour of 
our patients after responding biochemically to pyridoxine therapy was striking. This has previously been commented upon by Carson and Carré (1969) who also reported a case where attacks akin to petit mal have ceased, as occurred in Case 4.

Mudd and his co-workers (1970) have suggested that pyridoxine may enhance cystathionine synthase activity. They have shown modest increases in levels of activity of the enzyme in 2 patients who have responded to pyridoxine, but it is not certain whether these are significant increases or whether they merely reflect a biological variation in enzyme activity over a long time interval (3 years). Using similar methods, Gaull, Rassin, and Sturman (1969) failed to show enhanced activity of cystathionine synthase in patients who had responded to pyridoxine, but the methods may have been less sensitive.

Low fasting levels of serum folic acid were reported by Carey et al. (1968) in 4 out of 8 homocystinuric patients who were receiving no form of therapy. They found levels of $1.5-9 \cdot 0 \mathrm{ng} / \mathrm{ml}$, with a mean of $4.3 \mathrm{ng}$ In matched controls the range was $6 \cdot 1-11 \cdot 3 \mathrm{ng} / \mathrm{ml}$, mean 8 . Absorption and clearance studies of folic acid suggested overutilization of folate, thought to be due to increased remethylation of homocystine. They found a positive correlation between folate levels and IQ in their small number of patients. Carson and Carré (1969) did not find very low serum folate levels in their 9 untreated patients, though some levels were borderline. The levels in our 5 untreated patients were not outside the normal range. The lowest occurred in a severely retarded hospitalized boy whose retardation was probably due mainly to birth trauma, and not primarily to his homocystinuria. It is well known that patients in hospital have, on the average, lower serum folate levels than the normal population. It could be that this factor contributed to the low folate levels and positive correlation with the IQ noted by Carey et al. (1968), and that they were not, or not entirely, due to an increased rate of remethylation with higher plasma homocystine levels of more severely affected patients. The level of plasma homocystine has not been found to correlate well with the clinical severity of the disease (Carson, 1971).

The observation that serum folic acid activity may fall when homocystinurics are treated with pyridoxine has been made by Carson and Carré in 1969 and also in unpublished studies of Corcino et al. (1970). Carson and Carré (1969) found folate levels of 3 of their 9 pyridoxine-treated patients fell significantly during treatment. In 2 of these the peripheral blood remained normal. One patient developed megaloblastic anaemia; but she was also taking phenytoin and phenobarbitone, which reduce folate levels (Reynolds, 1968), so that the significance of this is not certain.

In all of our cases treated with pyridoxine in which folate levels were measured, there was a gradual and progressive decrease in serum and red cell folic acid activity to low levels. In no case was this accompanied by haematological changes. Changes in behaviour with marked irritability did occur, and these could be reversed by giving folic acid. These observations indicate that patients with homocystinuria who are being treated with pyridoxine should always have a small supplement of folic acid. One patient's good response to pyridoxine only became stabilized after folic acid was added to the treatment regimen, which suggests that intermittent remethylation of homocystine occurred with dietary folate availability.

The mechanism by which pyridoxine treatment lowers the serum and red cell folate levels is not known. A response to pyridoxine might be expected to reduce the rate of remethylation of homocysteine to methionine and thus reduce the utilization of folate. Recently, however, Finkelstein (1971), in a preliminary investigation, found that the enzyme $\mathrm{N}^{5}$ methyl tetrahydrofolatehomocysteine methyltransferase, which is one enzyme involved in the methylation of homocysteine to methionine, is inhibited by high concentrations of the substrate homocysteine. It is possible therefore that a pyridoxine-induced lowering of plasma homocysteine concentration could result in increased remethylation of homocysteine and provide an explanation for increased utilization of folate during therapy.

This work was supported in part by a grant from the Apex Foundation of Australia.

We are grateful to Dr. Barbara Arnold for the folate estimations, and to Mrs. D. Martiensen, and Mrs. S. Marler for technical assistance.

Ethnor Pty. Ltd. (Sydney) kindly made available supplies of Pyridoxine elixir.

\section{REFERENCES}

Barber, G. W., and Spaeth, G. L. (1969). The successful treatment of homocystinuria with pyridoxine. Fournal of Pediatrics, 75, 643.

Brenton, D. P., and Cusworth, D. C. (1971). The response of patients with cystathionine synthase deficiency to pyridoxine. In Inherited Disorders of Sulphur Metabolism, p. 264. Ed. by N. A. J. Carson and D. N. Raine. Churchill Livingstone, Edinburgh and London.

Carey, M. C., Fennelly, J. J., and FitzGerald, O. (1968). Homocystinuria. II. Subnormal serum folate levels, increased folate clearance and effects of folic acid therapy. American fournal of Medicine, 45, 26. 
Carson, N. A. J. (1971). Homocystinuria (cystathionine synthase deficiency) trial of treatment with oral pyridoxine and a normal diet. In Inherited Disorders of Sulphur Metabolism, p. 285. Ed. by N. A. J. Carson and D. N. Raine. Churchill Livingstone, Edinburgh and London.

Carson, N. A. J., and Carré, I. J. (1969). Treatment of homocystinuria with pyridoxine. Archives of Disease in Childhood, 44, 387.

Carson, N. A. J., and Neill, D. W. (1962). Metabolic abnormalities detected in a survey of mentally backward individuals in Northern Ireland. Archives of Disease in Childhood, 37, 505.

Corcino, J. J., Wada, J., Waxman, S., Gaull, G., and Herbert, V. (1970). Unpublished studies quoted in the American fournal of Medicine, 48,604 .

Finkelstein, J. D. (1971). Methionine metabolism in mammals. In Inherited Disorders of Sulphur Metabolism, p. 1. Ed. by N. A. J. Carson and D. N. Raine. Churchill Livingstone, Edinburgh and London.

Gaull, G. E., Rassin, D. K., and Sturman, J. A. (1969). Enzymatic and metabolic studies of homocystinuria: effects of pyridoxine. Neuropaediatrie, 1, 199.

Gerritsen, T., Vaughn, J. G., and Waisman, H. A. (1962). The identification of homocystine in the urine. Biochemical and Biophysical Research Communications, 9, 493.

Hollowell, J. G., Coryell, M. E., Knowlton Hall, W., Findley, J. K., and Thevaos, T. G. (1968). Homocystinuria as affected by pyridoxine, folic acid, and Vitamin B12. Proceedings of the Society for Experimental Biology and Medicine, $129,327$.

McCully, K. S. (1970). Importance of homocysteine-induced abnormalities of proteoglycan structure in arteriosclerosis. American Fournal of Pathology, 59, 181.

McKusick, V. A., Hall, J. G, and Char, F, (1971a). The clinical and genetic characteristics of homocystinuria. In Inherited Disorders of Sulphur Metabolism, p. 179 . Ed. by N. A. J. Carson and D. N. Raine. Churchill Livingstone, Edinburgh and London.
McKusick, V. A., Hall, J. G., and Char, F. (1971b). The clinical $\square$ and genetic characteristics of homocystinuria. In Inherited Disorders of Sulphur Metabolism, p. 193. Ed. by N. A. J. ? Carson and D. N. Raine. Churchill Livingstone, Edinburgh and London.

Mudd, S. H., Edwards, W. A., Loeb, P. M., Brown, M. S., and $\dddot{\square}$ Laster, L. (1970). Homocystinuria due to cystathionine synthase deficiency: the effect of pyridoxine. Fournal of Clinical Investigation, 49, 1762.

Mudd, S. H., Finkelstein, J. D., Irreverre, F., and Laster, L. (1964). Homocystinuria, an enzymatic defect. Science, 143, 1443.

Perry, T. L., Dunn, H. G., Hansen, S., MacDougall, L., and Warrington, P. D. (1966). Early diagnosis and treatment of $\bar{D}$ homocystinuria. Pediatrics, 37, 502.

Perry, T. L., Hansen, S., Love, D. L., Crawford, L. E., and Tischler, م) B. (1968). Treatment of homocystinuria with a low-methionine diet, supplemental cystine, and a methyl donor. Lancet, 2, 474. $\overrightarrow{0}$

Reynolds, E. H. (1968). Mental effects of anticonvulsants and folic acid metabolism. Brain, 91, 197.

Sardharwalla, I. B., Jackson, S. H., Hawke, H. D., and Sass- $\omega$ Kortsak, A. (1968). Homocystinuria: a study with lowmethionine diet in three patients. Canadian Medical Association fournal, 89, 731.

Spaeth, G. L., and Barber, G. W. (1965). Homocystinuria in a ta mentally retarded child and her normal cousin. Transactions $\infty$ of the American Academy of Ophthaimology and Otolaryngology, $\rightarrow$ 69, 912.

Turner, G., Dey, J., and Turner, B. (1967). Homocystinuriaa report of two Australian families. Australian Paediatric $\frac{\text { ? }}{2}$ Fournal, 3, 48.

Correspondence to Dr. B. Wilcken, Oliver Latham Laboratory, The Psychiatric Centre, Cox's Road, North Ryde, N.S.W. 2113, Australia. 